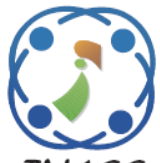

\title{
A Planar Monopole UWB Antenna with Partial Ground Plane for Retransmission-Based Chipless RFID
}

\author{
A K M Zakir Hossain ${ }^{1 *}$ \\ Win Adiyansyah Indra ${ }^{1}$ \\ J. A. Jamil Alsayaydeh ${ }^{1} \quad$ Safarudin Gazali Herawan $^{2}$ \\ ${ }^{I}$ Fakulti Teknologi Kejuruteraan Elektrik \& Elektronik (FTKEE), \\ Universiti Teknikal Malaysia Melaka (UTeM), Melaka, Malaysia \\ ${ }^{2}$ Industrial Engineering Department, Faculty of Engineering, Bina Nusantara University, Jakarta, Indonesia \\ * Corresponding author’s Email: zakir@utem.edu.my
}

\begin{abstract}
In this article, a microstrip-feed planar monopole ultra-wide band (UWB) antenna is proposed for the chipless RFID (CRFID) tag-reader systems with the intension to reduce the size of the tag. This antenna is keyhole shaped and small in size of $32 \times 20 \mathrm{~mm}^{2}$ compared with other existing antennas in the retransmission-based chipless CRFID system. The partial ground plane technique is applied here to obtain the bandwidth of $6.81 \mathrm{GHz}$ within the UWB frequency spectrum. The results show it is suitable for both identification and sensing application in the retransmission-based CRFID. The antenna has a good omni-directional radiation pattern with realized gain up to 4 $\mathrm{dBi}$ and the realized gain to antenna size ratio goes as high $0.39 / \mathrm{cm}^{2}$ which is comparatively higher than the other existing antennas in retransmission-based CRFID. The other feature of this antenna is it has the radiation efficiency up to $99 \%$ whereby it never goes below $96 \%$ throughout the working bandwidth and the measured antenna efficiency goes as high as $95 \%$. Furthermore, to check the suitability to apply in CRFID sensor application, the proposed antenna has been realized on three flexible substrates of polyimide, PET and paper, and very little deviations are found compared to the rigid Rogers RT 3003 substrate in terms of $S_{11}$, realized gain, efficiency and radiation pattern which is a proof of robustness of the design. This proposed antenna will motivate the researcher to develop a smaller sized UWB CRFID tags.
\end{abstract}

Keywords: Chipless RFID, Planar microstrip, UWB antenna, Bandwidth, Realized gain.

\section{Introduction}

In the industry and also, in the consumer level, the term Radio Frequency IDentification (RFID), is getting very familiar nowadays. The RFID is already in the market for many applications such as toll collection, inventory management, item tracking etc. Since the implementation of the RFID in the WWII to distinguish the friendly and the foe airplanes, this technique has become more mature due to the course of the time. The barcode technology is omnipresent in all products for identification. The barcode gives a good solution for item identification (IDing). However, this technology is prone to have many disadvantages such as vulnerable to wear and tear, denting, easy to tamper, always needs line of sight (LOS) for communication with the reader and etc. [1]. Recently, the researchers are interested in the RFID technology because all these abovementioned issues related to barcode system can be resolved by properly implementing the RFID system. The categorization of an RFID system is fully dependent on the nature of the tag. There are three different branches of RFID in terms of the power supply on board of the tag, (i) Active RFID (fully battery assisted tag), (ii) Semi-active RFID (partially battery assisted tag) and (iii) the passive RFID (no battery on board of the tag). The third kind is the cheapest and the only candidate so far to replace the barcode system [2]. However, the passive RFID comes with two types: Chipped RFID and chipless RFID (CRFID) and between these two types, the CRFID is at the forefront of the research to fully 


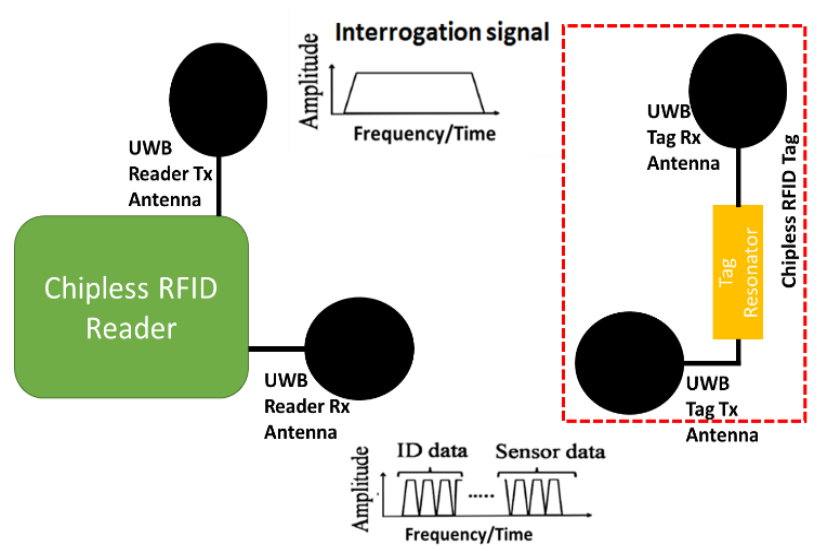

Figure. 1 Operational block diagram of a retransmission-based CRFID

replace the barcode system due to its cheapness and easy to fabricate. The CRFID tags my come with or without antenna(s). The CRFIDs which are without antenna are basically radar cross section (RCS) or backscatter based. The other type that comes with antenna is called the retransmission-based CRFID. Fig. 1 shows the general working block diagram of a retransmission-based RFID system. In Fig. 1 it can be seen that the CRFID system has four different antennas, two each for reader and the tag. However, due to the size of the antenna on board of the tag, the overall dimension of the tag gets comparatively bigger than the RCS based tags. Consequently, it is still a challenge for the RFID design researchers to make the receiver $(\mathrm{Rx})$ and transmitter $(\mathrm{Tx})$ antenna as small as possible while keeping the performance within the acceptable standard.

In 2009, the authors in [3] have proposed a novel retransmission-based chipless RFID system. In that system, the planar microstrip rectangular spiral resonators (MRSR) have been used for coding element along with two separate $\mathrm{Rx}$ and Tx antennas on the CRFID tag. The antennas are microstrip disc loaded monopole type with partial ground plane (PGP) whereby, the bandwidth (BW) of that antenna covered the whole UWB (3.1-10.7 GHz) spectrum. The size of the antenna is $66 \times 60 \mathrm{~mm}^{2}$ (length $\times$ width). Even though, there have been no 3D pattern and the gain Vs frequency response provided, from the $2 \mathrm{D}$ radiation pattern it is seen that the gain is around $0 \mathrm{~dB}$ which is very low considering the size of the antenna. The same disc loaded monopole antenna also has been used in [4] with the multi state rectangular spiral resonator (MSRSR) based tag which had a dimension of $90 \times 60 \mathrm{~mm}^{2}$. However, no gain and radiation pattern information has been revealed in that proposal. In the same way in [5], a rectangular UWB microstrip antenna has been proposed for a complementary split ring resonator
(CSRR) based chipless RFID tag. The authors have used babinet's principle to design that antenna. The size of the antenna is $36 \times 23 \mathrm{~mm}^{2}$ with a maximum gain of $2.45 \mathrm{dBi}$ at $7 \mathrm{GHz}$. The same antenna has been modified and used in [6] for a 3-state rectangular resonator based CRFID tag. However, the dimensions are comparatively big $(74.62 \times 25$ $\mathrm{mm}^{2}$ ) with maximum gain of $4.9 \mathrm{~dB}$. Yet, the comparatively high gain is due to merely the size of the antenna.

In [7], a co-planar waveguide (CPW) feed semicircle monopole antenna has been proposed for the CRFID tag. The antenna dimension is $32 \times 35 \mathrm{~mm}^{2}$ and have an omni-directional pattern. However, the information on the realized gain is missing in that proposal. Another CPW feed elliptical disc loaded monopole UWB antenna has been proposed in [8] for a modified circular split ring resonator (MCSRR) based chipless RFID tag. The peak gain has been seen around $2 \mathrm{dBi}$ for that antenna. However, the actual dimensions (total length and width) of the antenna are missing. The same CPW structure has been utilized for a CPW disc loaded monopole on the flexible Kapton film for a CPW rectangular spiral resonator based CRFID tag-sensor to measure the liquid concentration [9]. The dimension of the antenna is $51.1 \times 40.6 \mathrm{~mm}^{2}$. However, form the provided gain pattern it has been seen that the gain is around $0 \mathrm{~dB}$. Recently, a new shape called 'finger-tip shape antenna (FSA)' has been proposed in [10] where the authors has only revealed the partial S-parameter results to prove that this antenna may work throughout the UWB region. However, the dimensions and the gain information of the antenna are not presented in that proposal.

For all there above proposed antennas, some have good gain but due to their large size. Other antennas have smaller dimensions, however, suffered a low gain which would degrade the total yield of the CRFID system. This research focuses on developing an UWB antenna of small in size yet with comparatively high gain which would reduce the size of the CRFID tag significantly along with enhanced gain performance. To do so, in this article a new microstrip keyhole shaped antenna has been proposed, designed and realized through measurements for comparatively small size, higher realized gain, good antenna efficiencies and a good omni-directional pattern.

This article has been organized as: 2. Monopole Antenna Design (the design procedure and equations are described thoroughly in this section), 3. Results and Discussion (where, all the relevant and important results and responses are analysed and discussed in details), 4. Performance on Flexible 
Substrate (in this section, the performance of the proposed design on flexible substrates is observed and analysed) and 5. Conclusion (lastly, this research has been summarized and concluded in this section).

\section{Monopole antenna design}

The antenna named as the 'Keyhole shape' as the shape of the antenna patch mimics the keyhole structure. The design structure (both front and back side) of the antenna is illustrated in Fig. 2 with detailed dimensions. The substrate is used here as Rogers 3003 with a dielectric constant $\varepsilon_{\mathrm{r}}=3.0$, substrate height, $\mathrm{h}=0.51 \mathrm{~mm}$ and the loss tangent, $\tan \delta=0.001$. Fig. 2 (a) shows the front view of the antenna and Fig. 2 (b) shows the back view of the antenna with PGP dimensions. The steps of the design are illustrated in Fig. 3. To come up with this design, at first, a rectangular patch has been drawn (step 1). Later, a circular shape (radius, $\mathrm{R}=8 \mathrm{~mm}$ ) has been introduced with the rectangular patch and merged with it (step 2). Finally, the $50 \Omega$ transmission feed line is introduced and added with the keyhole shaped patch to finalize the design. The software used to simulate the design is CST MWS 2021.

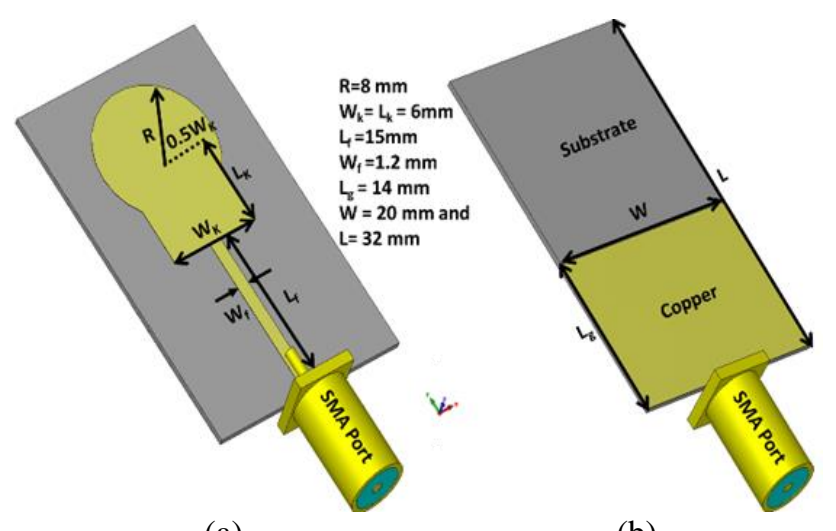

(a)

(b)

Figure. 2: (a) the front and (b) the back view of the antenna with detailed dimensions

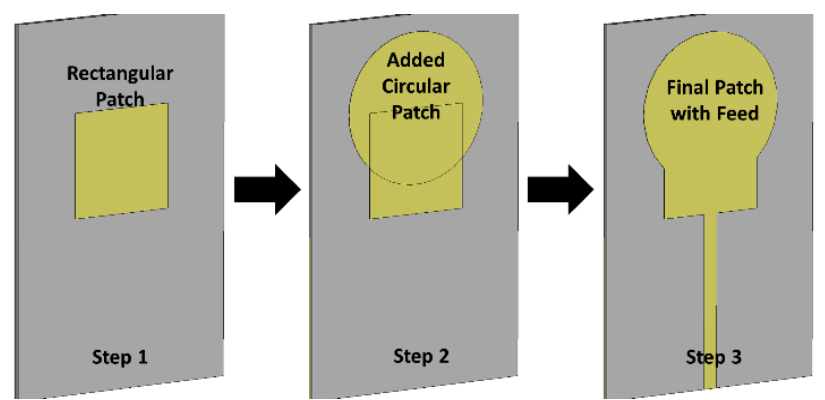

Figure. 3 Different stages of the antenna design

All the dimensions such as the length of the patch $\left(\mathrm{L}_{\mathrm{K}}\right)$ and the width of the patch $\left(\mathrm{W}_{\mathrm{K}}\right)$ have been calculated from Eqs. (1) to (5) as follows [1114],

$$
\begin{gathered}
W_{k}=\frac{C_{0}}{2 f_{c} \sqrt{\frac{\left(\varepsilon_{r}+1\right)}{2}}} \\
\varepsilon_{e}=\frac{\varepsilon_{r}+1}{2}+\frac{\varepsilon_{r}-1}{2}\left[1+12 \frac{h}{W_{p}}\right]^{-\frac{1}{2}} \\
L_{e}=\frac{C_{0}}{2 f_{c} \sqrt{\varepsilon_{e}}} \\
\Delta L=0.412 h \frac{\left(\varepsilon_{e}+0.3\right)\left(\frac{W_{k}}{h}+0.264\right)}{\left(\varepsilon_{e}-0.258\right)\left(\frac{W_{k}}{h}+0.8\right)} \\
L_{k}=L_{e}-2 \Delta L
\end{gathered}
$$

Where, $\mathrm{C}_{0}$ and $\varepsilon_{e}$ are the free space speed of the light and used substrate's effective dielectric constant respectively. $f_{c}$ and $\mathrm{L}_{\mathrm{e}}$ are operating (centre) frequency and the effective length of the patch. The length $(\mathrm{Lg})$ and width $(\mathrm{W})$ of the PGP have been calculated from Eqs. (6) and (7) respectively. As the guided wavelength, $\lambda_{g}=24.4$ $\mathrm{mm}$ at the centre frequency of $6.5 \mathrm{GHz}$, the approximated length of the final antenna, $L=\frac{4 \lambda_{g}}{3}=$ $32 \mathrm{~mm}$.

$$
\begin{gathered}
L_{g}=6 h+L_{k} \\
W=W_{g}=6 h+W_{k}
\end{gathered}
$$

The radius $(\mathrm{R})$ of the added circular patches has been calculated by the following Eqs. (8) and (9) [15],

$$
\begin{gathered}
R=\frac{F}{\left\{1+\frac{2 h}{\pi \varepsilon_{r} F}\left[\ln \left(\frac{\pi F}{2 h}\right)+1.7726\right]\right\}^{\frac{1}{2}}} \\
F=\frac{8.791 \times 10^{9}}{f_{c} \sqrt{\varepsilon_{r}}}
\end{gathered}
$$

\section{Results and discussions}

Fig. 4 illustrates the simulated S-parameter $\left(S_{11}\right)$ responses for the different stages of the antenna design. At the stage 1, the antenna has only the rectangular patch with full ground plane (GP). The patch has been added with the $50 \Omega$ feed line 


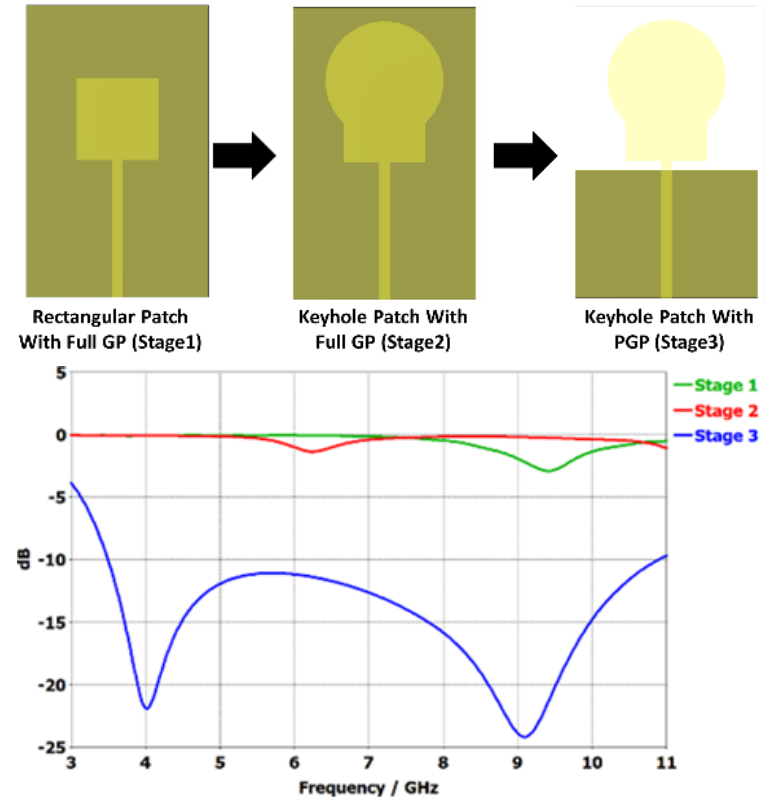

Figure. 4 S-Parameter Response for different stages of design

and simulated. It can be seen that the $S_{11}$ value is almost constant around $0 \mathrm{~dB}$ from 3 to $11 \mathrm{GHz}$. It implies that there is no resonance(s) from $3 \mathrm{GHz}$ to $11 \mathrm{GHz}$. At stage 2, the circular patch has been added and simulated again keeping the same full GP. It is seen that there are still no resonance(s) in the spectrum. Finally, at the stage 3, the full GP has been truncated and made as a PGP. This move made the key difference for the design. The stage-3's $\mathrm{S}_{11}$ response shows that the antenna is exhibiting a wide band working range.

After the initial confirmation from the simulated $S_{11}$ response, the antenna has been manufactured and the $S_{11}$ and the VSWR have been measured using the vector network analyser (VNA) model N5230 PNA-L. Later, the antenna has been connected in the anechoic chamber for the radiation pattern, realized gain and efficiency measurement. Fig. 5 comprises the manufactured antenna (front and back view) and the antenna in the anechoic chamber.

Fig. 6 (a) and (b) illustrates the simulated and measured $S_{11}$ and VSWR respectively of the designed antenna. A good agreement has been found between the simulated and measured data for both responses. A little deviation has been observed, however, merely due to the quality of the fabrication and manufacturing process. Fig. 6 (a) has revealed that the $S_{11},-10 \mathrm{~dB}$ measured value starts around $3.59 \mathrm{GHz}$ and it remains below $-10 \mathrm{~dB}$ until 10.28 $\mathrm{GHz}$. This made this design achieving an ultra-wide bandwidth (BW) of $6.69 \mathrm{GHz}$ with the centre frequency is approximately at $6.94 \mathrm{GHz}$. To analyse more, the VSWR response has been

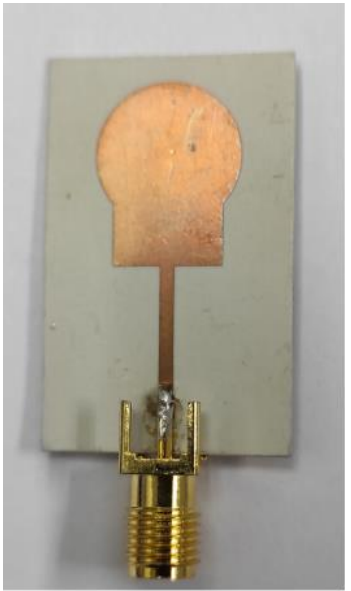

Front View

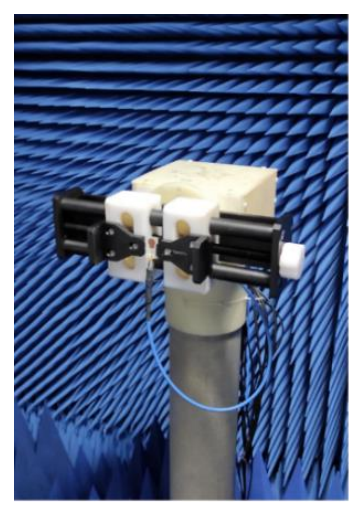

Front View

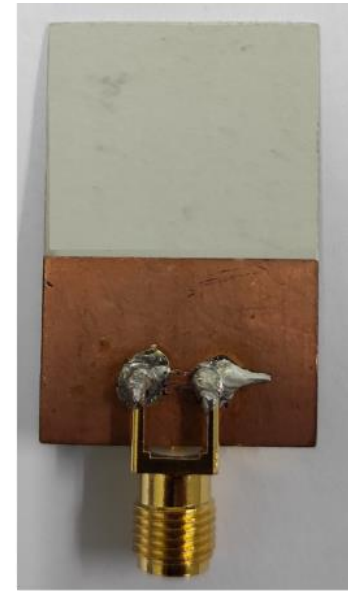

Back View

(a)

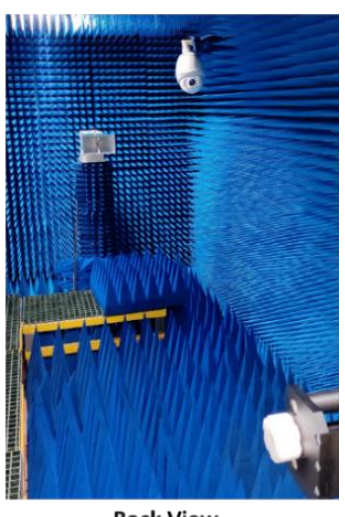

(b)
Figure. 5: (a) Manufactured antenna and (b) Manufactured antenna and measurement in the anechoic chamber

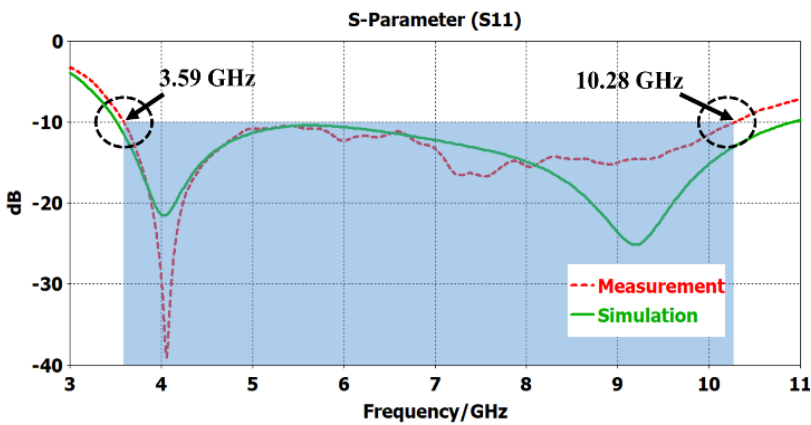

(a)

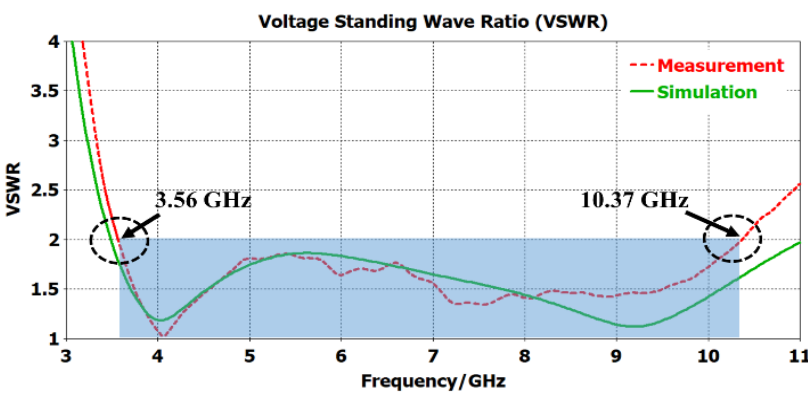

(b)

Figure. 6 The measured and simulated: (a) S11 and (b) VSWR of the antenna 


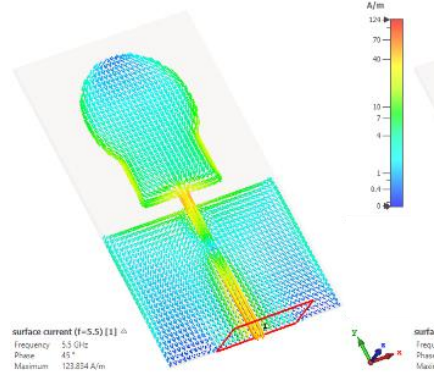

(a)
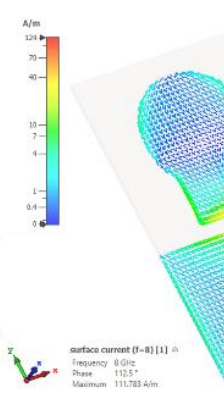

Figure. 7 The surface current accumulation at: (a) 5.5 $\mathrm{GHz}$ and (b) $8 \mathrm{GHz}$

investigated which is shown in Fig. 6 (b). The response fully tally with the $S_{11}$ response as the value is always below 2 from $3.56 \mathrm{GHz}$ to 10.37 $\mathrm{GHz}$ which gives a little higher BW of $6.81 \mathrm{GHz}$.

Similarly, Fig. 7 shows the high surface current accumulation of the antenna at $5.5 \mathrm{GHz}$ and $8 \mathrm{GHz}$ (inside the working band), justifying the design quality for this antenna. Since the determination of the antenna's resonance and the BW is justified, the next step is to investigate the performance of the antenna.

Fig. 8 (a), (b) and (c) comprise the simulated radiation efficiency and the total efficiency; the measured and simulated total efficiency, and the simulated and measured gain of the antenna respectively. It can be seen from Fig. 8 (a) that this design exhibits an excellent radiation efficiency which stays in between $96.5 \%$ to $99 \%$, throughout the entire BW. In addition, it is also seen that the simulated total efficiency of the antenna stays $90 \%$ and above for most parts of the entire working BW of the antenna. However, the measurement for the total efficiency deviates a bit, yet, it still reaches around $96 \%$ (see Fig. 8b). It actually indicates the antenna suffers less loss in the conversion from signal to radiation. Furthermore, form Fig. 8 (c) it is observed that the simulated and measured gain are also in agreement whereas the measured realized gain follows the same trend as the simulated realized gain and reaches up to $4 \mathrm{dBi}$. Fig. 9 (a) and (b) illustrate the 3D radiation patterns (normalized realized gain pattern) of the antenna at $5.5 \mathrm{GHz}$ and $8 \mathrm{GHz}$ respectively. From the 3D pattern it can be seen that most of the radiation is at the circumference of the radiation sphere. This shows that the radiation has an omni-directional pattern. Fig. 9 (c) and (d) are comprising the simulated and measured $\mathrm{E}$ and the $\mathrm{H}$-plane of the antenna in different frequencies of $5.5 \mathrm{GHz}$ and $8 \mathrm{GHz}$ respectively. The E-plane is supposed to be a bidirectional shape and Fig. 9 (c) and (d) show exactly the same. In both Figures it can be seen that the measured and the simulated H-plane 2-D polar

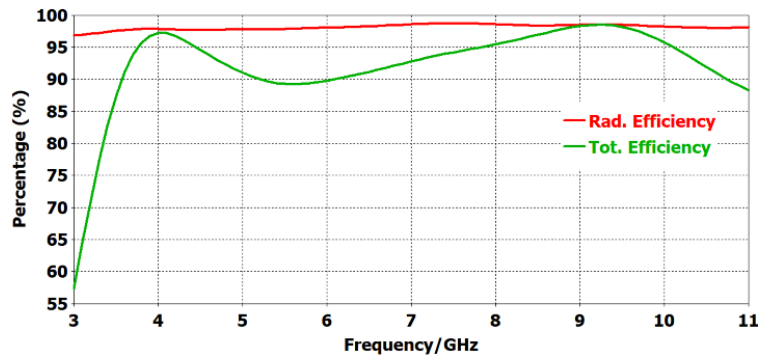

(a)

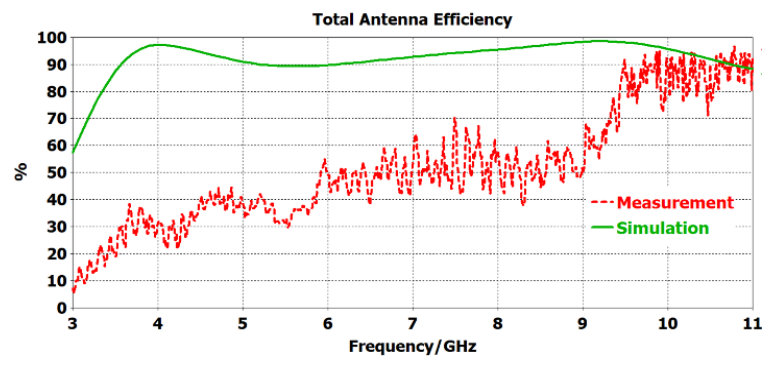

(b)

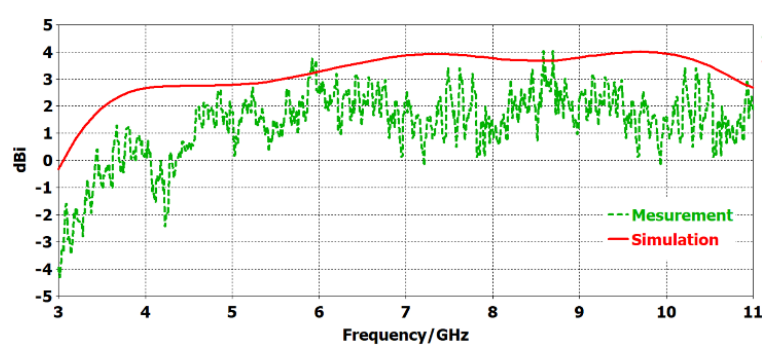

(c)

Figure. 8 Efficiencies and gain of the antenna: (a) simulated efficiencies, (b) simulated and measured total antenna efficiency, and (c) simulated and measured gain

patterns are in agreement. However, for the E-plane pattern in both figures, deviations are found between the simulated and measured values but still exhibiting the bidirectional nature. All these 3D and 2-D pattern's responses prove that the antenna exhibits an omni-directional radiation pattern which is necessary for the chipless retransmission type tags to communicate with the CRFID reader. Table 1 summarizes the comparison among the existing chipless RFID tag antennas and this proposed work in terms of antenna size, antenna efficiency, realized gain and gain to antenna size ratio. From the Table 1 it can be seen that the proposed work has the smallest size among all other existing works and exhibits maximum realized gain of $4 \mathrm{dBi}$ which is so far comparatively high considering the small size of the proposed antenna in this work. Furthermore, from the Table 1 it is seen that the ratio between the realize gain and antenna size (antenna area) is also the highest compared with other existing antennas in the retransmission-based CRFID with a value of $0.39 / \mathrm{cm} 2$, whereby the closest existing one is only $0.166 / \mathrm{cm} 2$ which is $57.4 \%$ less than the proposed 


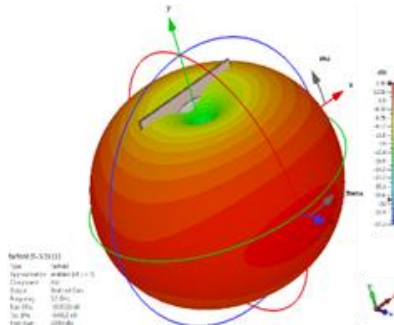

(a)

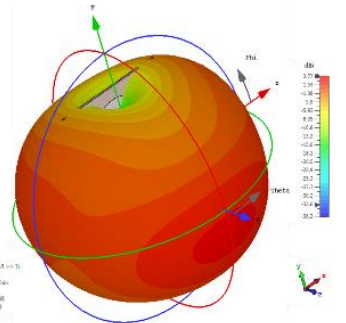

(b)

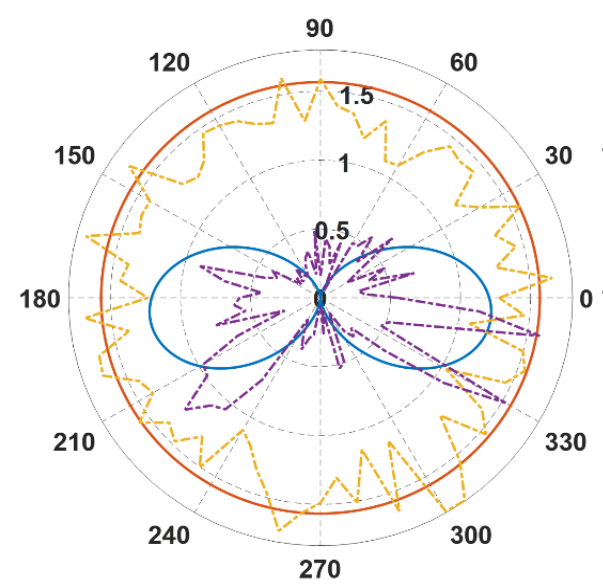

(c)
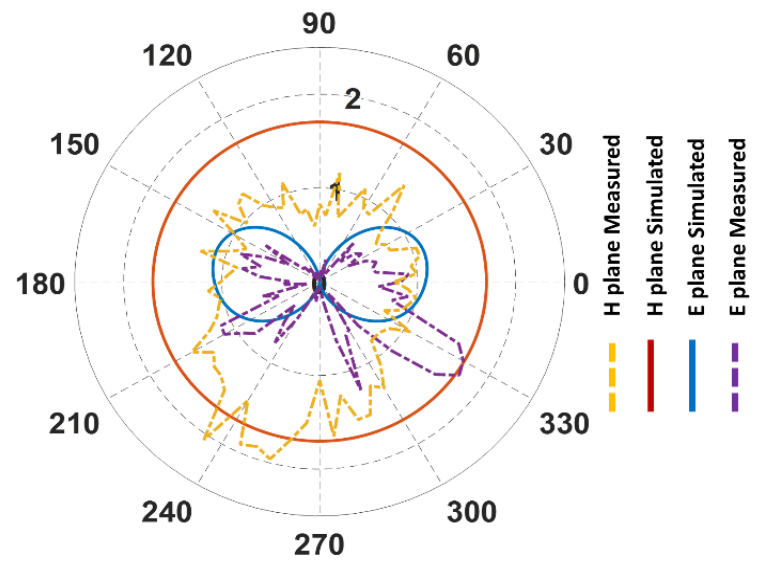

(d)

Figure. 9 Simulated and measured far-field radiation pattern at $5.5 \mathrm{GHz}$ and $8 \mathrm{GHz}$ : (a) 3-D pattern at $5.5 \mathrm{GHz}$, (b) 3-D pattern at $8 \mathrm{GHz}$, (c) Simulated and measured Eand $\mathrm{H}$-plane pattern at $5.5 \mathrm{GHz}$, and (d) Simulated and measured E- and $\mathrm{H}$-plane pattern at $8 \mathrm{GHz}$

design. This indicates that even though the antenna is small but it generates comparatively higher gain. One more noticeable observation can be found from table 1 that in no proposal the authors has revealed the antenna efficiency information whereas this parameter is very important to assess the performance of the antenna. Nevertheless, this proposed design can produce the measured antenna efficiency as high as $96 \%$ which is well above the acceptable range (above $80 \%$ ) for any antenna to perform well.
Table 1. Comparison between existing and proposed

\begin{tabular}{|c|c|c|c|c|}
\hline Ref & $\begin{array}{c}\text { Dimension } \\
\left(\mathrm{mm}^{2}\right)\end{array}$ & $\begin{array}{c}\text { Antenn } \\
\text { a } \\
\text { Efficie } \\
\text { ncy } \\
(\%)\end{array}$ & $\begin{array}{c}\text { Realized } \\
\text { Gain } \\
(\mathrm{dBi}) \\
/(\text { linear })\end{array}$ & $\begin{array}{c}\text { Realize } \\
\text { gain to Size } \\
\text { Ratio } \\
\left(\text { gain/ } \mathrm{cm}^{2}\right)\end{array}$ \\
\hline$[3]$ & $66 \times 60$ & na & $0 / 1$ & 0.0253 \\
\hline$[4]$ & $90 \times 60$ & na & na & na \\
\hline$[5]$ & $36 \times 23$ & na & $\begin{array}{c}2.45 / 1.75 \\
8\end{array}$ & 0.15 \\
\hline$[6]$ & $74.62 \times 25$ & na & $4.9 / 3.1$ & 0.1666 \\
\hline$[7]$ & $35 \times 32$ & na & na & na \\
\hline$[8]$ & na & na & $2 / 1.58$ & na \\
\hline$[9]$ & $51.1 \times 40.6$ & na & $0 / 1$ & 0.048 \\
\hline$[10]$ & na & na & na & na \\
\hline $\begin{array}{c}\text { This } \\
\text { work }\end{array}$ & $\mathbf{3 2 \times 2 0}$ & $\mathbf{9 6}$ & $\mathbf{4 / 2 . 5 1}$ & $\mathbf{0 . 3 9}$ \\
\hline
\end{tabular}

\section{Performance on flexible substrate}

Another prospect of the CRFID is that this type may also be utilized to create the sensors for different parameters such as temperature, moisture, humidity, food quality $\left(\mathrm{P}^{\mathrm{H}}\right)$, water quality, dielectric

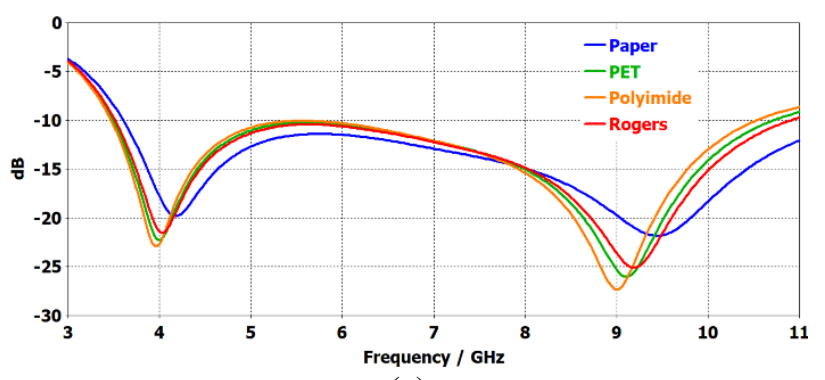

(a)

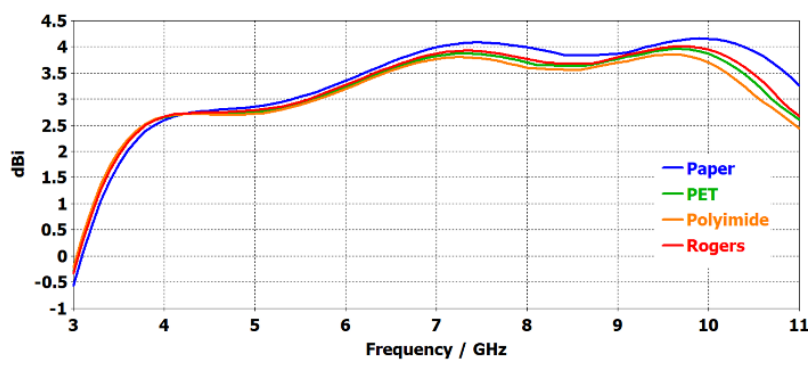

(b)

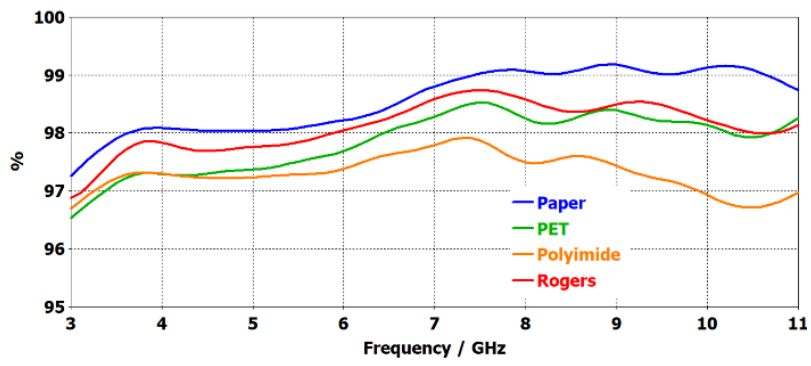

(c)

Figure. 10: The (a) S11, (b) realized gain and (c) radiation efficiencies for different substrates 
sensor and many other. Sometimes, it is necessary to realize the CRFID tags onto the flexible substrates due to necessity of the operating principle of the sensor. Because of this fact and as the proposed design is intended to be used for all CRFID application, it is crucial that the capabilities of this proposal on the flexible substrates is investigated. To do so, the antenna is modelled on three different flexible substrates, i) Polyimide $\left(\varepsilon_{r}=3.5, \mathrm{~h}=\right.$ $0.5 \mathrm{~mm}, \tan \delta=0.001 \quad$ ); ii) Polyethylene terephthalate $(\mathrm{PET})\left(\varepsilon_{r}=3.2, \mathrm{~h}=0.5 \mathrm{~mm}, \tan \delta=\right.$ $0.0009)$; and iii) plain paper $\left(\varepsilon_{r}=2.31, \mathrm{~h}=\right.$ $0.5 \mathrm{~mm}, \tan \delta=0.001$ ), and are investigated by simulating in CST MWS. In Fig. 10, the necessary responses are presented.

Fig. 10 (a) comprises the $S_{11}$ response of the proposed antenna on different substrates. It can be seen that the antenna still exhibits the UWB operating frequency range, however, with an expected little difference, merely due the change in the substrate. Almost entire UWB, the $S_{11}$ response of the antenna for all substrates is below $-10 \mathrm{~dB}$.

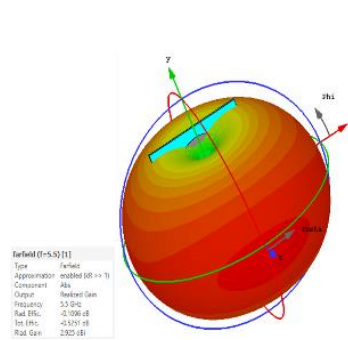

(a)

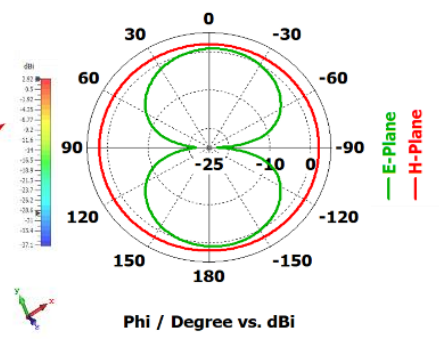

(b)

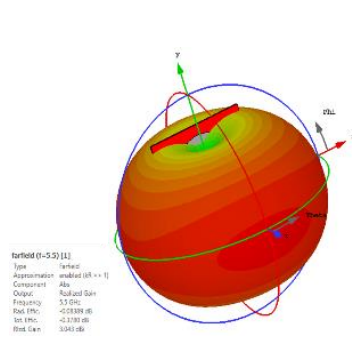

(c)

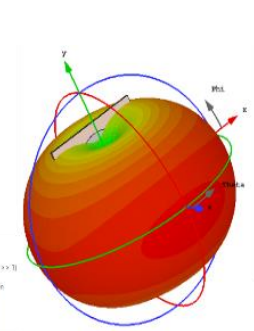

(e)

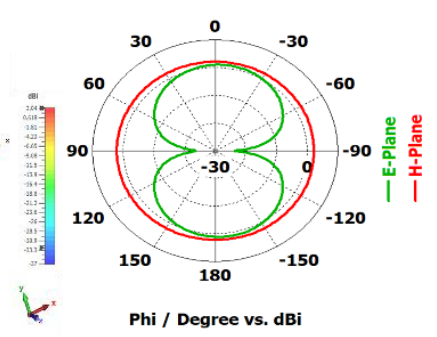

(d)

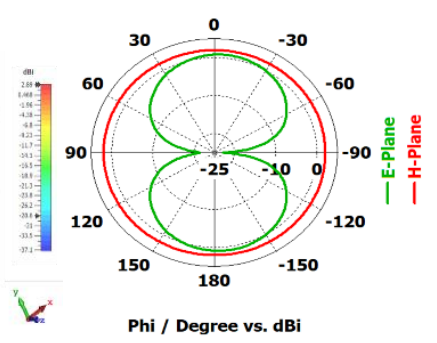

(f)
Figure. 11 The 3-D and 2-D farfield radiation pattern for different substrates: (a), (b) PET, (c), (d) Paper, and (e), (f) Polyimide
Furthermore, the $-10 \mathrm{~dB}$ BW is increased significantly by going beyond $11 \mathrm{GHz}$ while the design is realized on the paper substrate. Fig. 10 (b) reveals the realized gain response for different substrate. In similar way, it is seen that the maximum realized gain is around $4 \mathrm{dBi}$, with only an exception for paper substrate, where, a little increase in the gain reaching up to $4.2 \mathrm{dBi}$ has been observed. Furthermore, the radiation efficiency illustrated in Fig. 10 (c) shows the same agreement. It is seen that the all the radiation efficiencies never go below $96 \%$ and for the paper substrate, it goes as high as $99.2 \%$.

Fig. 11 comprises the simulated 3-D and 2-D (polar) farfield radiation for different substrates. All the three 3-D responses exhibit the expected omnidirectional pattern whereby their corresponding polar representation of the $\mathrm{E}$ - and the H-plane patterns also quite in agreement and justifies the omni-directional nature of the farfield radiation pattern. After all the responses are analysed in this section, it is quite evident that the design is robust and can be realized on different substrate without losing or altering much of the performance of the antenna.

\section{Conclusion}

A planar keyhole shape microstrip UWB antenna for the chipless UWB RFID tag has been designed and realized here. The results are verified both in simulation and also in measurement and good agreements have been found for different responses. The antenna is comparatively smaller in size while maintaining a comparatively good gain throughout the UWB spectrum reaching up to $4 \mathrm{dBi}$. The realized gain to antenna sized ratio of $0.39 / \mathrm{cm}^{2}$ is also higher among the existing antennas in the retransmission-based CRFID. This indicates that even though the antenna is small, it produces comparatively higher gain. Moreover, the efficiencies are also very good throughout the whole BW reaching up to $99 \%$ for rigid Rogers 3003 substrate. In addition, an extended investigation, by realizing the proposed antenna on different flexible substrates, has revealed the robustness of the design Furthermore, for the paper substrate the gain enhances up to $4.2 \mathrm{dBi}$ and the simulated efficiency reaches as high as $99.2 \%$. It is conclusive that the proposed antenna can be realized on different flexible substrates without sacrificing much of the performance. So, it is apparent that the proposed antenna is suitable for all the tag and as well as reader Tx and Rx application for the retransmissionbased RFID applications in UWB frequencies related to identification and CRFID sensors as well. 


\section{Conflicts of Interest}

The authors declare no conflict of interest.

\section{Author Contributions}

The authors' contributions are as follows: "Conceptualization, A K M Zakir Hossain; methodology, J. A. Jamil Alsayaydeh; software, A K M Zakir Hossain; validation, Win Adiyansyah Indra and Safarudin Gazali Herawan; formal analysis, Safarudin Gazali Herawan; investigation, A K M Zakir Hossain and J. A. Jamil Alsayaydeh; resources, Win Adiyansyah Indra; writing - original draft preparation, A K M Zakir Hossain; writingreview and editing, Safarudin Gazali Herawan; funding acquisition, Win Adiyansyah Indra.

\section{Acknowledgments}

This work has been funded by the grant JURNAL/2019/FTKEE/Q00047 from the center for research and innovation management (CRIM), University Teknikal Malaysia Melaka (UTeM).

\section{References}

[1] A. K. M. Z. Hossain, M. I. Ibrahimy, and S. M. A. Motakabber, "Spiral Resonator for Ultra Wide Band Chipless RFID Tag", In: Proc. of International Conf. on Computer and Communication Engineering, pp. 281-283, 2014.

[2] A. K. M. Z. Hossain, S. M. A. Motakabber, and M. I. Ibrahimy, "Microstrip Spiral Resonator for the UWB Chipless RFID Tag", In: Prog in Systems Engineering, pp. 355-358, 2015.

[3] S. Preradovic, I. Balbin, N. C. Karmakar, and G. F. Swiegers, "Multiresonator-based Chipless RFID System for Low-Cost Item Tracking", IEEE Transactions on Microwave Theory and Techniques, Vol. 57, No. 5, pp. 1411-1419, 2009.

[4] S. Majidifar, A. Ahmadi, O. Sadeghi-Fathabadi, and M. Ahmadi, "A Novel Phase Coding Method in Chipless RFID Systems", AEU International Journal of Electronics and Communications, Vol. 69, No. 7, pp. 974-980, 2015.

[5] Z. Ma, J. Yang, C. Chen, and C. Yang, "A Retransmitted Chipless Tag Using CSRR Coupled Structure", Microsystem Technologies, Vol. 24, No. 10, pp. 4373-4382, 2018.

[6] W. M. Abdulkawi and A. A. Sheta, "High Coding Capacity Chipless Radiofrequency Identification Tags", Microwave and Optical
Technology Letters, Vol. 62, No. 2, pp. 592599, 2020.

[7] Y. F. Weng, S. W. Cheung, T. I. Yuk, and L. Liu, "Design of Chipless UWB RFID System Using A CPW Multi-resonator", IEEE Antennas and Propagation Magazine, Vol. 55, No. 1, pp. 13-31, 2013.

[8] M. S. Bhuiyan and N. C. Karmakar, "AnEfficient Coplanar Retransmission Type Chipless RFID Tag Based on Dual-band MCSRR", Progress in Electromagnetics Research C, Vol. 54, No. 2, pp. 133-141, 2014.

[9] Z. Li and S. Bhadra, "A 3-bit Fully Inkjetprinted Flexible Chipless RFID for Wireless Concentration Measurements of Liquid Solutions", Sensors and Actuators, Vol. 299, No. 11, pp. 111581-111587, 2019.

[10] A. K. M. Z. Hossain, M. I. Ibrahimy, S. M. A. Motakabber, S. M. K. Azam, and M. S. Islam, "Multi-resonator Application on Size Reduction for Retransmission-based Chipless RFID Tag", Electronics Letters, Vol. 57, No. 1, pp. 26-29, 2021.

[11] M. S. Islam, M. I. Ibrahimy, S. M. A. Motakabber, and A. K. M. Z. Hossain, "A Rectangular Inset-Fed Patch Antenna with Defected Ground Structure for ISM Band", In: Proc. of the 2018 7th International Conf. on Computer and Communication Engineering, pp. 104-108, 2018.

[12] M. S. Islam, M. I. Ibrahimy, S. M. A. Motakabber, A. K. M. Z. Hossain, and S. M. K. Azam, "Microstrip Patch Antenna with Defected Ground Structure for Biomedical Application", Bulletin of Electrical Engineering and Informatics, Vol. 8, No. 2, pp. 586-595, 2019.

[13] S. M. K. Azam, M. S. Islam, A. K. M. Z. Hossain, and M. Othman, "Monopole Antenna on Transparent Substrate and Rectifier for Energy Harvesting Applications in 5G", International Journal of Advanced Computer Science and Applications, Vol. 11, No. 8, pp. 84-89, 2020.

[14] B. K. Medhal, P. Jayappa, and J. Shivamurthy, "Design of Minkowski Fractal Iteration in Monopole Patch Antenna", International Journal of Intelligent Engineering and Systems, Vol. 13, No. 5, pp. 549-559, 2020.

[15] A. K. M. Z. Hossain, N. B. Hassim, S. M. K. Azam, M. S. Islam, and M. K. Hasan, "A Planar Antenna on Flexible Substrate for Future 5G Energy Harvesting in Malaysia", International Journal of Advanced Computer 
Received: April 26, 2021. Revised: June 9, 2021.

Science and Applications, Vol. 11, No. 10, pp.

151-155, 2020. 